\title{
How Do Men Talk about Taking Parental Leave? Evidence from South Korea, Spain, and the U.S.
}

\author{
Xiana Bueno and Eunsil Oh
}

\section{Introduction}

Allowing working fathers, as well as mothers, to combine family and work responsibilities has contributed to a closing of the gender gap at home and in the labor market (Bünning 2015) and improves the bond between parents and their children (O'Brien 2009). However, the use of parental leave by men is still far from a common practice in many societies. The persistence of traditional gender-role ideology and its social norms, the rigidity of labor markets and organizational culture, and existing gender inequality in public institutions, such as in family policies, are part of the explanation. The gender dimension at the individual and institutional levels is highly interconnected.

In recent decades, some countries have made an effort to provide parental leave benefits to employed men. We know little, however, about how men talk about the leave system and use parental leave. In this chapter, we aim to extend our understanding of men's views on parental leave use by putting their individual narratives in the macro-level context where they live in order to better understand how institutions and individuals are connected. To do this, we analyze how childless men and fathers of one child talk about taking leave and use leave policies. Using 80 personal in-depth interviews, we compare men's narratives and reasoning in South Korea, Spain, and the United States. These three countries represent distinctive macro-institutional contexts, labor market structures and cultures, and

\footnotetext{
X. Bueno $(\bowtie)$

Centre d'Estudis Demogràfics, Carrer de Ca n'Altayó, Edifici E2, Universitat Autònoma de Barcelona, Barcelona, Spain

e-mail: xbueno@ced.uab.es

E. Oh

University of Wisconsin-Madison, Madison, WI, USA
}

(C) The Author(s) 2022

M. Grau Grau et al. (eds.), Engaged Fatherhood for Men, Families and Gender

Equality, Contributions to Management Science,

https://doi.org/10.1007/978-3-030-75645-1_9 
gender-role models, and the findings suggest how these three features are linked to interviewees' narratives in different ways.

Although this paper focuses on men, we acknowledge that men's decision making regarding parental leave cannot be understood outside the couple dimension. Both partners' ideologies and employment characteristics are crucial for fertility decisions and childcare arrangements (Bueno and Grau-Grau 2021; Singley and Hynes 2005; Bygren and Ann-Zofie 2006; Kaufman and Almqvist 2017). In this chapter, we examine the couple dimension based on what our male interviewees reflect about their partners. This work contributes to a better understanding of the reasoning behind couples' use of parental leave from men's perspectives and will offer insight for the design of future policies and strategies to reduce gender inequality.

\section{Theoretical Approaches and Literature Review}

To understand men's intentions and use of parental leave under their macro-level context, we draw on the main theoretical approaches that past literature has highlighted as influencing the use of parental leave. We agree that gender is at the center of understanding how individuals use parental leave (Singley and Hynes 2005; Valarino et al. 2018). However, we need to understand other dimensions labor market and financial conditions, cultural aspects, and institutional factors - to fully understand the role gender plays in how people understand parental leave and use it.

\subsection{Workplace Environment}

Numerous studies have shown how labor market structure and workplace environment shape the use of parental leave by men. For example, working in the private sector implies additional constraints not present in the public sector (Beglaubter 2017). Additionally, studies emphasize the role of organizational culture and employers in explaining how men use parental leave (Haas et al. 2002; Bygren and Ann-Zofie 2006). The use of leave by other coworkers (Lapuerta et al. 2011), an employer's willingness to facilitate work-life balance (Crompton 2006), or working in a family-friendly environment (Escot et al. 2012) have positive effects on men's parental leave use. A recent study comparing intentions with parental leave use showed that men who received organizational support from their companies to plan parental leave ended up realizing their parental leave plans (Horvath et al. 2017). Although higher income positively relates to leave-taking behavior (Lapuerta et al. 2011), the higher the job status (i.e., managerial positions) the less likely leavetaking becomes, mainly because the opportunity costs for a career increase (Escot et al. 2012). For this analysis, we expect that in settings with rigid work norms such 
as Korea and, to a lesser extent, the U.S., respondents would be more reticent to use family policies regardless of job status, than in Spain.

\subsection{Individual- and Couple-level Dynamics}

Beyond individual characteristics, couple or household characteristics are crucial to obtain a full understanding of men's parental leave use. Based on household income, couples evaluate the affordability of taking childcare leave (Reich 2010; Meil et al. 2017). Additionally, men and women evaluate their educational and occupational status to determine the comparative advantages of the partners and their opportunity costs (Becker 1981). Similarly, fathers with partners who have a stronger position in the labor market are more likely to take parental leave than other fathers are (Reich 2010). The bargaining model predicts that each partner has power to trade with the other resulting from their relative earnings and time availability (Lundberg and Pollak 1996). According to this model, we expect that in countries where the dualearner model persists as the most common couples' economic arrangement even after parenthood, as in Spain and the U.S., men would be more prone to take parental leave than in Korea.

\subsection{Cultural Explanations}

There is wide agreement among scholars on how individuals' subjective characteristics, such as identity, individual norms, or ideology, influence parental leave behaviors (Doucet 2009). In particular, what has been traditionally considered "good" mothering (caregiving) and fathering (breadwinning) relates to cultural norms (Craig and Mullan 2010; Kühhirt 2012). Conversely, some studies observing emerging unconventional patterns in parents' childcare arrangements have claimed that structural factors, such as an economic crisis, might force a gender-role change at the societal or institutional level (Chesley 2011; Dominguez-Folgueras et al. 2018). The emerging pattern of gender-egalitarian fathers that adopt an active role in childcare and subscribe to the "new fatherhood ideal" (Petts et al. 2017) is associated with higher educational levels and younger ages (Escot et al. 2014). At the interactional level, men and women match their behaviors according to what they expect from each other and socially with respect to parental responsibilities (Singley and Hynes 2005). In this sense, we expect higher involvement of men in taking parental leave in countries where gender-role attitudes have evolved toward greater egalitarianism, such as Spain or the U.S., compared to more traditional gender-role settings like Korea. 


\subsection{Welfare System and Policies}

The institutional context - characteristics of leave, length, wage replacement rate, and requirements to qualify - shapes individuals' attitudes toward welfare programs (Valarino et al. 2018). A gendered paid parental leave system, by which mothers get longer leaves than fathers, reinforces traditional gender roles (Lapuerta et al. 2011). In the U.S. context, the fact that paid childcare leave is often offered only to mothers leads women to take further responsibilities in childcare after the end of the leave (Fox 2009). Beyond the parental leave system, the provision of public childcare supply or tax benefits after parenthood are important factors to be considered (Baizán 2009). In countries in which the welfare state does not promote gender equality, more traditionalism in gender roles occurs after parenthood (Neilson and Stanfors 2014). Therefore, we expect to observe a significant divergence between the Spanish respondents, whose parental leave system is expanding in favor of men's rights, and the Korean and American respondents, whose available options are limited in this regard.

\section{Three Macro-Institutional Contexts: Korea, Spain, and the U.S.}

\subsection{Labor Force Participation and Gender Equality}

Among the three countries, and despite having a population with highest proportion of highly educated women in the world, Korea also has the lowest female participation rate: $63.4 \%$ of females between 25 and 34 years old were in the labor force in 2012 (the reference year of our sample) (OECD 2018a). A high gender wage gapmen earn $36.3 \%$ more than women, compared to $19.1 \%$ and $8.6 \%$ in the U.S. and Spain, respectively - is also a distinguishing pattern for Korea. The high level of unemployment in Spain during the peak of the 2008 global recession is noteworthy, at $28.7 \%$ in 2012 for men (slightly lower for women), compared with 5.3\% and $8.2 \%$ for Korean and American males, respectively. The instability of the Spanish labor market and the economy cannot be neglected as a key factor driving women to be economically active regardless of their gender-role attitudes. The lower gender wage gap in Spain should cause this factor to interfere less in Spanish parents' parental leave use negotiation than in that of parents in the other two countries. Spain has the highest female participation rate of the three countries $(85.3 \%)$. The U.S. falls between Korea and Spain, with $74.1 \%$ female labor force participation.

The Gender Gap Index (GGI) from the World Economic Forum (WEF) measures countries' gender inequality based on economic participation, educational attainment, health and survival, and political empowerment. According to the GGI (Hausmann et al. 2012), Spain and the U.S. hold similar rankings, 26 and 22 (out of 135), respectively. Korea, however, reflects a context in which gender inequality 
is high, ranking 108. Additionally, gender-role attitudes reflect that Spain is the most gender egalitarian, followed by the U.S. and Korea (World Values Survey 20102014). Lastly, the division of household labor shows that Korean men spend only 45 min per day in unpaid work, while their American and Spanish counterparts spend $150 \mathrm{~min}$ and $146 \mathrm{~min}$, respectively. In terms of paid work, Korean men spend $422 \mathrm{~min}$ in paid work per day on average, American men spend $335 \mathrm{~min}$, and Spanish men spend 236 min (OECD 2018b).

\subsection{Family Policies}

Fully paid statutory allowances for mothers and fathers exist only in Korea and in Spain. In 2012, in both countries, policies provided mothers with a longer period of paid leave than fathers. Maternity leave lasts almost 13 weeks (90 days) for Korean mothers and 16 weeks for Spanish mothers. In the Spanish case, 10 out of the 16 weeks were able to be transferred to the father in 2012 (year of the interviews). However, between 2008 and 2011, less than $2 \%$ of fathers used transferable weeks from maternity leave (Flaquer and Escobedo 2014).

Regarding parental leave, it is important to distinguish between paid and unpaid leave. Paid paternity leave is substantially shorter. Korean fathers as of 2021 can take 10 days of paid paternity leave. Conversely, although Spain has offered two paid days to new fathers since the 1930s, in recent times, a progressive effort has been made to improve fathers' leave length. In 2007, two-week paternity leave was implemented; in 2017, the government approved four-week leave for fathers, which became 5 weeks in July 2018, 8 weeks in April 2019, 12 weeks in January 2020 and 16 weeks in January 2021, achieving parity with maternity leave. In the U. $\mathrm{S}$., there is no national legislation in this regard, although some states and municipalities offer paid leave policies at the local level. Paid leave, if any, is generally provided at employers' discretion and is often intended exclusively for mothers and not fathers. Nevertheless, according to a Department of Labor Survey from 2000, only $24 \%$ of private U.S. employers offered some kind of paid maternity-related leave, and only $12 \%$ offered "leave for parents to care for a newborn" (Ray et al. 2008) (Table 1).

The characteristics of parental leave differ substantially across countries. Childcare leave in Korea and Spain can be taken full-time or part-time. For the latter, there is a salary reduction proportional to the reduction in working hours. However, while Korea offers wage replacement in the full-time version, in Spain and the U.S., full-time leave is unpaid. Additionally, leave length differs substantially. Korea offers up to 52 paid weeks (1 year). The first 13 weeks are paid at $80 \%$ and from the 14th to $52 \mathrm{nd}$ week at $40 \%$. In contrast, Spain is one of the most generous countries offering unpaid leave. Regarding full-time leave, Spanish parents can take 
Table 1 Country context indicators: Korea, Spain and the U.S.

\begin{tabular}{|c|c|c|c|}
\hline & Korea & Spain & U.S. \\
\hline \multicolumn{4}{|l|}{ Labor market and time use } \\
\hline - Female labor force participation rate, 25-34 years old [1] & 63.4 & 85.3 & 74.1 \\
\hline - Male unemployment rate, 25-34 years old [1] & 5.3 & 28.7 & 8.2 \\
\hline - Gender wage gap $[1,2]$ & 36.3 & 8.6 & 19.1 \\
\hline - Men's time spent in unpaid work (minutes per day) [3] & 45 & 145.9 & 150.2 \\
\hline - Men's time spent in paid work (minutes per day) [3] & 421.9 & 236.2 & 334.8 \\
\hline \multicolumn{4}{|l|}{ Gender inequality and attitudes } \\
\hline - Country ranking (1-135) on the gender gap index (GGI) [4] & 108 & 26 & 22 \\
\hline $\begin{array}{l}\text { - Percent of males considering that the best childcare option for } \\
\text { children under school age is "Both mother and father part-time" [5] }\end{array}$ & 5 & 16 & 4 \\
\hline $\begin{array}{l}\text { - Disagreement with the statement "When jobs are scarce, men } \\
\text { should have more right to a job than women" }(\%)[6]\end{array}$ & 22.7 & 82.1 & 69.9 \\
\hline \multicolumn{4}{|l|}{ Family policies } \\
\hline - Paid maternity leave (in weeks, in 2012) & 12.9 & 16 & 0 \\
\hline - Paid paternity leave (in weeks, in 2012) & 0.4 & 2.1 & 0 \\
\hline - Paid parental leave (in weeks, in 2012) & 52 & 0 & 0 \\
\hline - Unpaid parental leave (in weeks, in 2012) & 0 & 156 & 12 \\
\hline
\end{tabular}

Source: [1] OECD Stats 2012; [2] The gender wage gap is defined as the difference between male and female median wages divided by the male median wage; [3] OECD Stats (Korea 2009; Spain 2009-10; U.S. 2014); [4] World Economic Forum 2012; [5] International Social Survey Programme (ISSP) 2012 - Family and Changing Gender Roles IV [6] World Values Survey 2010-2014

52 weeks with protection of their former job position and up to 156 weeks (3 years) with job protection, though they are not guaranteed the same position. For part-time leave, Spanish parents could reduce their working hours between 1/8 and 1/2 until the child is 8 years old (in 2012). ${ }^{1}$ Despite these policies, for the period 2005-2009, fathers in Spain started unpaid parental leave for $0.3 \%$ of yearly births compared with 5-6\% for mothers (Escot et al. 2014). American parents face much less beneficial conditions. The federal Family Medical Leave Act (FMLA) has provided 12 full-time continuous weeks of unpaid leave to new parents since 1993. Employees only qualify for FMLA leave if they have been working for at least 1 year at the company and the company has more than 50 employees. Such restrictions imply that approximately $40 \%$ of U.S. workers in 2012 were not covered by the FMLA (Klerman et al. 2014), and those workers largely belong to low-income families (Ray et al. 2008). Some states complement the FMLA by offering partial-payment or more flexible conditions.

\footnotetext{
${ }^{1}$ Unpaid part-time leave can be taken until 12 years old as of 2020 .
} 


\section{Data and Methods}

Our data were drawn from 80 in-depth interviews conducted in three countries in 2012. The interviewees were recruited through snowball sampling. Interviews were conducted face-to-face and typically lasted between 60 and $120 \mathrm{~min}$. All interviews were voice-recorded and transcribed in full by a native speaker from each country. Sampling and interviewing in Korea and Spain were carried out by the authors, who are both sociologists. Fieldwork in the U.S. was performed by sociology graduate students. The sample includes 43 childless males and 37 fathers with one child. Given the small sample size, we sought to avoid having too much heterogeneity within our sample. All the respondents are highly educated, heterosexual, nativeborn, urban men aged 24-35 in stable unions. ${ }^{2}$ Higher education is defined as the completion of tertiary education (a university degree or post-secondary vocational program). The selected ages-24-35 years old-capture the life-stage period in which family formation is highly prominent. In addition, we restricted the sample to individuals who are not full-time students, who are not expecting a child, do not have children from a previous relationship, and who are not separated, divorced, or widowed. Equal numbers of interviews were conducted in large urban areas in each country: Seoul and Busan in Korea, Madrid and Barcelona in Spain, and Boston and New York City in the U.S. The interview questions touched on various topics: current or most recent employment of the interviewee and his/her partner; union formation, fertility ideals, intentions, and reasoning; household and childcare division of labor; gender-role attitudes; and views on family policies.

In the first stage, thematic coding was performed using qualitative software (Dedoose). In the second stage, we inductively coded and wrote extensive detailed memos about the narratives offered by participants. In the third stage, the authors shared their analyses and had an in-depth discussion. The data were rigorously revisited as many times as necessary to ensure the correct interpretation of each interview.

\section{Results}

\subsection{Spain and the U.S.: The Salience of Leave Availability}

As Table 2 summarizes, our analysis reveals three important findings. First, for both Spanish and American interviewees who use and plan to use parental leave, the rationale behind their intentions is often the partner's relative resources on the labor market and whether leave is paid or unpaid. In Spain, none of the males (and very

\footnotetext{
${ }^{2}$ While all respondents in the Korean and American samples are married, the Spanish sample includes both married and stable cohabiting couples to reflect the diverse union formation patterns of the European context.
} 
Table 2 Results

\begin{tabular}{l|l|l|l}
\hline & Korea & Spain & U.S. \\
\hline $\begin{array}{l}\text { Usage } \\
\text { and } \\
\text { intention }\end{array}$ & $\begin{array}{l}\text { Paid paternity leave } \\
\text { (5 days): Taken or plan to } \\
\text { take it } \\
\text { Partially paid parental } \\
\text { leave (1 year): No inten- } \\
\text { tion of using leave by } \\
\text { childless and none of the } \\
\text { fathers (except one) used it }\end{array}$ & $\begin{array}{l}\text { Paid paternity leave } \\
\text { (2 weeks): Taken (plan to } \\
\text { take it) almost by all } \\
\text { Full-time unpaid paren- } \\
\text { tal leave (up to 3 years } \\
\text { old): Not an option (eco- } \\
\text { nomic uncertainty) } \\
\text { Part-time unpaid paren- } \\
\text { tal leave (up to 8 years } \\
\text { old): Childless more flex- } \\
\text { ible than fathers (none } \\
\text { used it) }\end{array}$ & $\begin{array}{l}\text { Paid paternity leave: } \\
\text { Taken when available } \\
\text { Childcare arrange- } \\
\text { ments after paid leave: } \\
\text { Childless more rigid than } \\
\text { fathers (many made job } \\
\text { adjustments) }\end{array}$ \\
\hline Narratives \\
& $\begin{array}{l}\text { Policies are good, but } \\
\text { workplace norms (rigidity } \\
\text { and long-working hours) } \\
\text { do not legitimate use of } \\
\text { parental leave for men } \\
\text { There are strong gender- } \\
\text { essentialist norms }\end{array}$ & $\begin{array}{l}\text { High unemployment and } \\
\text { economic uncertainty lead } \\
\text { men to talk about the cost } \\
\text { and benefit of using leave } \\
\text { Gender egalitarian norms } \\
\text { are prevalent }\end{array}$ & $\begin{array}{l}\text { There are strong gender- } \\
\text { essentialist norms } \\
\text { regarding motherhood } \\
\text { for young children } \\
\text { Individuals' responsibil- } \\
\text { ity is highlighted due to } \\
\text { the lack of policies }\end{array}$ \\
\hline
\end{tabular}

Source: Project interviews

few of their partners, according to interviewees) considered taking (or took) full-time parental leave. Regardless of couples' gender ideology, the economic uncertainty that has arisen in the Spanish context due to the economic crisis and the lack of wage replacement during childcare leave explain the very low usage of this policy option. Childless respondents show more flexible opinions regarding part-time unpaid parental leave or reduction of working hours. Nevertheless, those who expressed positive intentions to take part-time leave-as well as their partners-seem to be aware that their ultimate decision will be subject to two conditions: his and his partner's job situation and employers' willingness at the time of making the decision and their economic circumstances at that time. Bruno is an example. He is 27, childless, and works as a primary school teacher.

[Would you take part-time unpaid parental leave?] If I could afford it, I would not mind at all. Of course! But, as I've said before, the school administration is not very flexible in these cases, not even with women. I can't even imagine how they would be with men.

Among Spanish fathers, those who actively engage in childcare express that this is mainly due to their partners' employment circumstances rather than to their ideological commitment to gender egalitarianism. Interestingly, a majority of Spanish fathers who adjust their working conditions instead of using parental leave are selfemployed. Likewise, those fathers who report an arrangement in which he did not take unpaid leave and she did do not necessarily hold traditional gender-role attitudes.

Compared with more traditional narratives among American childless men, many fathers from the U.S. sample made some labor-market adjustments when they had 
their first child. The actual childcare arrangements employed by the American fathers in the sample indicate three different strategies. The first strategy is that of dual-earner couples in which both partners hold occupations with a relatively similar status and male respondents report having a gender-egalitarian distribution of tasks at home. Both partners return to work after their paid leave allowance. A second common strategy is that of couples in which the female partners take a much longer parental leave than their husbands. Some of these women have unpaid parental leave available in their work place, while others take a deliberately extended period of unemployment or stop working for an open-ended period of time. These women act as primary caregivers for periods that range between 6 and 15 months or until their child(ren) goes to school. Some fathers expressed a hope that their partners would return to the labor market in the near future to continue their career development. There is also a small group of involved fathers. Fathers who are more involved in their child's care and who make adjustments to their labor force participationtaking FMLA leave and switching to a part-time job-have partners who hold a more stable and better paid position in the labor market than them. Often after considering the cost of daycare or nannies, these couples decide that it will be the man that will make the adjustment.

In the American sample, a clear majority of childless respondents expressed that they had no intention of stopping full-time work. In general, respondents intend to change their work hours, but these changes often consist in cutting back overtime rather than reducing work hours. For example, childless American respondents plan to respect their 40-h work week but said that they might adjust their schedules by travelling less for work, arriving home earlier, eliminating weekend or after-hours work, or trying to work remotely from home. There is an assumption of intensive mothership during early childhood that leads childless men to not even envision themselves as parental leave-takers. Edward put it this way: "I'm really looking forward to having little kids, but I'm not looking forward to having a baby." Nevertheless, a small group held more gender-egalitarian attitudes, such as Jeffrey, a 30-year-old childless actor and acting teacher.

\footnotetext{
I don't have any kind of preconceptions about which parent should be taking care of the kids. I really don't think that matters ... I would say if you can arrange it so either you're both working part-time and with complimentary schedules so that you can spend a lot of time with the child, then that would be great, or if one parent is working and the other's not-although I guess that would be less ideal because I certainly wouldn't want to get into an arrangement where I was working 80 hours a week, and Laura wasn't working at all, and I never saw my child. I wouldn't find that acceptable.
}

Nevertheless, rational choice based on partners' relative resources was often present among American respondents with a more egalitarian ideology. Some of them stated that the partner who would make job adaptations would be the one whose adjustment would make more sense economically for the finances of the family.

With few exceptions, the majority of our interviewees in the three countries took or plan to take the paid paternity allowance after the birth of their child. Money is an important driving motivation to fully utilize the available leave system. However, despite having a paid leave system, not taking days off after a child's birth is a 
practice more common in Korea than in Spain or the U.S. This is related to workplace-influenced attitudes and assumptions surrounding the legitimacy of using leave, such as feeling unable to stop working (often among the self-employed or those in higher status positions) or being afraid of penalties for taking leave (i.e., weak relationship with employer). As Kitae, a 33-year-old journalist and father of one child, argues, "When no one uses leave and it is kind of awkward to use leave, it is obviously hard to utilize a long leave." Even though Korea has one of the most generous childcare leave policies in the world, the rigidity of its labor market norms and long working hours position men's intentions and actions far from considering taking childcare leave. Paradoxically, in the U.S., with no statutory policies, fathers in our American sample took longer paternity leaves than fathers in Korea. Regardless of recent changes in the family policy system, the comparison shows that workplace culture as well as attitudes toward who should use leave strongly shape the ways in which men use and imagine using leave.

\subsection{Korea and the U.S.: The Salience of Gender-Role Attitudes}

The belief in gender-essentialist norms - the male breadwinner, female caregiver model-emerged in most of the interviews with the Korean men. Ascribing to relatively more gender-essentialist attitudes, Korean men see the gendered pattern of using parental leave as natural and believe that leave should be used only by mothers because they are more fit for child rearing. There are strong and internalized social and cultural expectations that being a good father means sustaining a stable income. For Minho, a 31-year-old childless architect, this is clear: "It is natural to focus on working when you become a father. I will be working harder for my family, for my child, as a head of the family."

In contrast to the Korean males, none of the males in the Spanish sample are in a partnership that reflects traditional gender-roles. Highly educated men do not expect to have a stay-at-home partner, mostly because of their relatively egalitarian genderrole attitudes but also because of the convenience of having both partners economically support the household. As noted before, some childless Spanish men have positive intentions of taking leave, as do their partners (according to them). It is notable that all those who reported negative intentions - except two - also expressed their belief that their female partners would be willing to take part-time leave (or sometimes full-time). While some of these males and their partners hold gender-traditional values, others show more gender-egalitarian conceptions. For the latter, it is the weaker position of their female partners in the labor market (i.e., unemployed, working part-time or precariously) that explains their negative intention to take leave rather than preconceived ideas about their gender roles within the family. Interestingly, men who reported that they and their partners would not take 
leave were highly educated and career-oriented, and their partners had similar trajectories.

Conversely, many of the childless American respondents emphasize the ideal arrangement as one in which they "can afford that she can stay at home." Genderessentialist beliefs about the ideal childcare arrangement are taken for granted, leading many American males to see intensive mothership during very early childhood as normal and, as a result, that they have no responsibility to take parental leave. Indeed, several childless respondents in their narratives imply that their active involvement as fathers will be more needed when their children are toddlers or older. Relying on a "biological discourse" based on the breastfeeding argument and a "strong bond between the mother and the child" these males consider themselves less useful for childcare during the early childhood period. Thomas, a 33-year-old substitute teacher, represents an extreme case of this idea. I think that I would not want to change diapers. [Laughter] I think that would be her job.
When it comes to like guy stuff like teaching him to play sports and how to ride a bike, I said
earlier, you know that, I would definitely be happy to take responsibility when it comes to
that.

[Can you imagine what proportion of the child rearing she might do versus you?]

I think it would be 50/50. She'll do the female stuff, I'll do the male stuff. [Chuckles] I think it would be half and half.

Among childless American respondents, it is easy to identify the "flexible egalitarian" attitude in which couples emphasize individual freedom as their rationale. Taylor, among others, clearly reflects this stance: "It's really a choice, so if she wants to pursue being a full-time mother, that's fine. If she wants to pursue having a career, that's fine as well." Male ambivalence about the female's role_as long as it makes financial sense-reinforces the assumption that the role of main caregiver continues to be a woman's. However, while some of our interviewees affirmed that their partners have always desired to become full-time mothers, others emphasized that their partners were conflicted about whether to continue their careers or become stay-at-home mothers. Some males expressed their feeling of needing to know that they could be the sole provider for their family if necessary, while others with a flexible egalitarian attitude expressed a feeling of regret at the idea that their female partners might abandon their careers and education efforts to become full-time mothers.

\subsection{Institutional Context and Individual Narratives}

The macro-institutional contexts interfere substantially with parental leave use and intentions in Spain and the U.S. There is a distinct difference between childless men and fathers in Spain: Respondents in both groups mentioned a desire for equal and longer maternity and paternity leaves, but only fathers desired longer leaves for mothers. American respondents have a much more limited vision of ideal family 
policies. For American interviewees, ideal policies often involved paid maternity leave, and it was rare to insist on longer available leave for fathers.

Both Spanish and American respondents emphasize the need for workplaces to offer more time flexibility in allowing employees to manage their own schedule, work remotely, or work compressed schedules. Spanish respondents in particular complained about the inequality between the public and private sector regarding the application of statutory policies. It is known that many employees in the private sector, mainly men but also women, experience penalties when taking parental leave (Lapuerta et al. 2011).

The scenario is quite different for the American context, since the U.S. does not provide statutory paid parental leave (except for some states and municipalities), and benefits generally depend on employers. Many of the childless American interviewees are not aware of the family policies that their companies offer, and such policies did not play any particular role in their decision to join their companies. When asked about how family-friendly their workplaces are, parental leave is not the first thing they mention; rather, they discuss flexible working hours or the ability to leave work when an emergency occurs. These men do not think about childcare on a daily basis. They know about their companies' parental leave policies only from workmates that have transitioned to parenthood recently. Most of the time, they refer exclusively to maternity leave. Indeed, the idea is so uncommon that some males use the term "male maternity leave" to refer to paternity leave. David, for example, who is an accountant, never heard about a man taking time off in his company: "I've never come across anybody taking off, a man taking off. I don't know. I've never brought it up to anybody, but I've never known anybody that has." Many of these men reported that they would feel uncomfortable asking for time off. David adds later, "I might feel a little uncomfortable actually going to them saying, 'Hey can I take a few months off cuz I've got kids.' [Why?] Again I feel that's just more of a, I don't know. Sometimes I feel they might look at me the wrong way. 'You're not the woman, so why are you taking time off?'." For many interviewees, the reason that stops them from using the policies is their anticipation that this will hurt their careers or limit promotion possibilities. Most of them declare that they would feel comfortable using time off if they saw other male employees using it. Some of the fathers found out after becoming fathers the work-life reconciliation measures that their company provides. Flexible time, on-site daycare, or financial assistance to pay for childcare were some of the measures available to fathers working in more familyfriendly companies.

\section{Implications}

This study finds three important narratives about the intended use and use of parental leave among childless men and fathers from three different countries - Korea, Spain and the U.S. First, in the Korean context, strong masculinity norms and workplace norms make Korean men unwilling to take parental leave. They work (or plan to 
work) even harder after parenthood as a result of their more traditional gender-role values, which makes the gender approach prevalent in this context. This creates a mismatch between labor-market institutions and family policies because implementing paid parental leave has not resulted in more frequent leave-taking by men. Second, in the Spanish context, the lack of wage replacement in a scenario of economic uncertainty makes the relative resources perspective prevalent regardless of respondents' gender-role ideology and gender dynamics at home. Spanish policies fall short in supporting dual-earner couples in resolving work-life conflict. Nevertheless, some involved fathers made unofficial adjustments to their careers, most of them working in self-employment. Third, in the U.S., the lack of statutory policies and the prevalence of a gendered culture in companies, combined with a strong liberalized and individualistic labor market, reinforce gender essentialist norms towards family. This work culture in a context of more gender egalitarian attitudes gives place to flexible egalitarian attitudes toward women among male respondents. While most American respondents do not envision a change in their full-time work schedules, they show a preference for, or at least an ambivalence about, their female partners working part-time or leaving the workforce after childbirth.

Our findings point to both scholarly and practical recommendations. Future study should investigate how "good" fatherhood is shaped by and, in turn, shapes the available parental leave for men. In relation to this, our results indicate the power of institutions and policies. Gender-equal statutory policies shape how workers think about being treated equally at the workplace. When the usage of leave is legitimized for both men and women, we expect to see a merging of ideals about a good worker and a good parent.

\section{References}

Baizán P (2009) Regional child care availability and fertility decisions in Spain. Demogr Res 21 (27):803-842

Becker GS (1981) A treatise on the family. Harvard University Press, Cambridge

Beglaubter J (2017) Balancing the scales: negotiating Father's parental leave use. Can Rev Sociol 54(4):476-496

Bueno X, Grau-Grau M (2021) Why is part-time unpaid parental leave (still) gendered? narratives and strategies of couples in Spain. J Fam Issues 42(3):503-526. https://doi.org/10.1177/ 0192513 X20918286

Bünning M (2015) What happens after the 'daddy months'? Fathers' involvement in paid work, childcare, and housework after taking parental leave in Germany. Eur Sociol Rev 31 (6):738-748

Bygren M, Ann-Zofie D (2006) Parents' workplace situation and fathers' parental leave use. J Marriage Fam 68(2):363-372

Chesley N (2011) Stay-at-home fathers and breadwinning mothers: gender, couple dynamics, and social change. Gend Soc 25(5):642-664

Craig L, Mullan K (2010) Parenthood, gender and work-family time in the United States, Australia, Italy, France, and Denmark. J Marriage Fam 72(5):1344-1361 
Crompton R (2006) Employment and the family. The reconfiguration of work and family life in contemporary societies. Cambridge University Press, Cambridge

Dominguez-Folgueras M, Jurado-Guerrero T, Botía-Morillas C (2018) Against the odds? Keeping a nontraditional division of domestic work after first parenthood in Spain. J Fam Issues 39 (7):1855-1879

Doucet A (2009) Dad and baby in the first year: gendered responsibilities and embodiment. Ann Am Acad Pol Soc Sci 624(1):78-98

Escot L, Fernández-Cornejo JA, Lafuente C, Poza C, Jurado-Guerrero T, Botía-Morillas C (2012) Willingness of Spanish men to take maternity leave. Do firms' strategies for reconciliation impinge on this? Sex Roles 67(1-2):29-42

Escot L, Fernández-Cornejo JA, Poza C (2014) Fathers' use of childbirth leave in Spain. The effects of the 13-day paternity leave. Popul Res Policy Rev 33(3):419-453

Flaquer L, Escobedo A (2014) Licencias parentales y política social de la paternidad en España. Cuadernos de Relaciones Laborales 32(1):69-99

Fox B (2009) When couples become parents: the creation of gender in the transition to parenthood. University of Toronto Press, Toronto

Haas L, Allard K, Hwang P (2002) The impact of organizational culture on men's use of parental leave in Sweden. Community Work Fam 5(3):319-342

Hausmann R, Tyson LD, Zahidi S (2012) The global gender gap report 2012. World Economic Forum, Geneva

Horvath LK, Grether T, Wiese BS (2017) Fathers' realizations of parental leave plans: leadership responsibility as help or hindrance? Sex Roles 79(3-4):163-175

Kaufman G, Almqvist A-L (2017) The role of partners and workplaces in British and Swedish Men's parental leave decisions. Men Masculinities 20(5):533-551

Klerman JA, Daley K, Pozniak A (2014) Family and medical leave in 2012: technical report. Abt Associates, Washington, DC. https://www.dol.gov/sites/dolgov/files/OASP/legacy/files/ FMLA-2012-Technical-Report.pdf

Kühhirt M (2012) Childbirth and the long-term division of labour within couples: how do substitution, bargaining power, and norms affect parents' time allocation in West Germany? Eur Sociol Rev 28(5):565-582

Lapuerta I, Baizán P, González MJ (2011) Individual and institutional constraints: an analysis of parental leave use and duration in Spain. Popul Res Policy Rev 30(2):185-210

Lundberg S, Pollak RA (1996) Bargaining and distribution in marriage. J Econ Perspect 10 (4):139-158

Meil G, Romero-Balsas P, Rogero-García J (2017) Why parents take unpaid parental leave: evidence from Spain. In: Česnuitytė V, Lück D, Widmer ED (eds) Family continuity and change: contemporary European perspectives. Palgrave Macmillan, London, pp 245-267

Neilson J, Stanfors M (2014) It's about time! Gender, parenthood, and household divisions of labor under different welfare regimes. J Fam Issues 35(8):1066-1088

O'Brien M (2009) Fathers, parental leave policies, and infant quality of life: international perspectives and policy impact. Ann Am Acad Pol Soc Sci 624(1):190-213

OECD (2018a) Population with tertiary education (indicator). https://doi.org/10.1787/0b8f90e9-en. Accessed 22 May 2018

OECD (2018b) Time spend in paid and unpaid work, by sex (indicator). https://stats.oecd.org/. Accessed 22 May 2018

Petts RJ, Shafer KM, Lee E (2017) Does adherence to masculine norms shape fathering behavior? J Marriage Fam 80(3):704-720

Ray R, Janet C. Gornick, John Schmitt (2008) Parental leave policies in 21 countries. Assessing generosity and gender equality. Report. Center for Economic and Policy Research. http://cepr. net/publications/reports/plp 
Reich N (2010) Who cares? Determinants of the fathers' use of parental leave in Germany, HWWI research paper 1-31, Hamburg

Singley SG, Hynes K (2005) Transitions to parenthood: work-family policies, gender, and the couple context. Gend Soc 19(3):376-397

Valarino I, Duvander A-Z, Haas L, Neyer G (2018) Exploring leave policy preferences: a comparison of Austria, Sweden, Switzerland, and the United States. Social Politics: International Studies in Gender, State \& Society 25(1):118-147

World Values Survey (2010-2014) World Values Survey Wave 6: 2010-2014. http://www. worldvaluessurvey.org/wvs.jsp

Open Access This chapter is licensed under the terms of the Creative Commons Attribution 4.0 International License (http://creativecommons.org/licenses/by/4.0/), which permits use, sharing, adaptation, distribution and reproduction in any medium or format, as long as you give appropriate credit to the original author(s) and the source, provide a link to the Creative Commons license and indicate if changes were made.

The images or other third party material in this chapter are included in the chapter's Creative Commons license, unless indicated otherwise in a credit line to the material. If material is not included in the chapter's Creative Commons license and your intended use is not permitted by statutory regulation or exceeds the permitted use, you will need to obtain permission directly from the copyright holder. 